\title{
Study of Cytochrome P450 2E1 and its Allele Variants in Liver Injury of Nondiabetic, Nonalcoholic Steatohepatitis Obese Women
}

\author{
NELSON M VARELA ${ }^{1}$, LUIS A QUIÑONES ${ }^{1}$, MYRIAM ORELLANA $^{1}$, \\ JAIME PONIACHIK ${ }^{2}$, ATTILA CSENDES ${ }^{3}$, GLADYS SMOK $^{4}$, RAMÓN RODRIGO $^{1}$, \\ DANTE D CÁCERES ${ }^{5}$ and LUIS A VIDELA ${ }^{1}$
}

\author{
${ }^{1}$ Molecular and Clinical Pharmacology Program, Institute of Biomedical Sciences, Faculty of Medicine, \\ University of Chile \\ 2 Department of Medicine, University of Chile Clinical Hospital \\ ${ }^{3}$ Department of Surgery, University of Chile Clinical Hospital \\ ${ }^{4}$ Department of Pathological Anatomy, University of Chile Clinical Hospital \\ ${ }^{5}$ Epidemiology Division, School of Public Health, University of Chile, Santiago, Chile
}

\begin{abstract}
CYP2E1 enzyme is related to nonalcoholic steatohepatitis (NASH) due to its ability for reactive oxygen species production, which can be influenced by polymorphisms in the gene. The aim of this study was to investigate hepatic levels, activity, and polymorphisms of the CYP2E1 gene to correlate it with clinical and histological features in 48 female obese NASH patients. Subjects were divided into three groups: (i) normal; (ii) steatosis; and (iii) steatohepatitis. CYP2E1 protein level was assayed in microsomes from liver biopsies, and in vivo chlorzoxazone hydroxylation was determined by HPLC. Genomic DNA was isolated for genotype analysis through PCR. The results showed that liver CYP2E1 content was significantly higher in the steatohepatitis $(45 \% ; \mathrm{p}=0.024)$ and steatosis $(22 \% ; \mathrm{p}=0.032)$ group compared with normal group. Chlorzoxazone hydroxylase activity showed significant enhancement in the steatohepatitis group $(15 \%$, $\mathrm{p}=0.027$ ) compared with the normal group. c2 rare allele of $R$ sal/Pst 1 polymorphisms but no C allele of Dral polymorphism was positively associated with $\mathrm{CHZ}$ hydroxylation, which in turn is correlated with liver CYP2E1 content $(r=0.59 ; p=0.026)$. In conclusion, $c 2$ allele is positively associated with liver injury in NASH. This allele may determine a higher transcriptional activity of the gene, with consequent enhancement in pro-oxidant activity of CYP2E1 thus affording liver toxicity.
\end{abstract}

Key terms: steatohepatitis, NASH, CYP2E1, obesity, genotype, chlorzoxazone.

\section{INTRODUCTION}

NASH is a progressive liver pathology associated to etiologic factors such as obesity, hyperlipidemia, insulin resistance, and type-II diabetes mellitus, with obesity being the most important (James and Day, 1998; Matteoni et al., 1999; Angulo et al., 1999; Ratziu et al., 2000). This disorder is observed in patients with no history of significant alcohol consumption, however histologically it resembles alcohol-induced liver injury (Ludwig et al., 1980). Fatty liver, the earliest and most prevalent stage of $\mathrm{NASH}$, is thought to sensitize the liver to additional necroinflammatory insults, thus promoting disease progression to steatohepatitis and cirrhosis (Matteoni et al., 1999; Angulo et al., 1999). A number of metabolic parameters are related to NASH. These include imbalances in amino acid, glucose, and antiketogenic and ketogenic hormones in portal blood, mitochondrial dysfunction (Matteoni et al., 1999), pro-

Corresponding Author: Dr. Luis Quiñones S., Laboratory of Chemical Carcinogenesis and Pharmacogenetics, IFT, Molecular and Clinical Pharmacology Program, Institute of Biomedical Sciences, Faculty of Medicine, University of Chile, P.O. Box 70111, Santiago 7, Chile. Tel: 56-2-6817756; Fax: 56-2-7372783; E-mail: lquinone@med.uchile.cl 
inflammatory cytokine release (Ratziu et al., 2000), oxidative stress, and CYP2E1 induction (Ludwig et al., 1980; Weltman et al., 1998; Videla et al., 2004a). CYP2E1 has a significant role in the biotransformation of ethanol and other xenobiotics, the gluconeogenesis from ketones, and fatty acid oxidation, being a major microsomal source of ROS (González, 2005). This enzyme is induced by pesticides, thyroid hormones, alcohol and ketones, the latter usually found in obesity, insulin resistance, and diabetes (Pagano et al., 2002; Fernández et al., 2003; Wang et al., 2003), thus contributing to liver pathologies such as alcoholic liver disease and non-alcoholic steatohepatitis (Lieber, 2004; Ishii, 2004).

From the pathogenic point of view, CYP2E1-derived ROS could represent a crucial factor in determining liver injury, particularly when antioxidant defenses are depleted (Videla et al., 2004a), thus contributing to the enhancement in lipid peroxidation, protein carbonylation, and DNA oxidation observed in NASH patients (Robertson et al., 2001). In addition, higher CYP2E1 activity is seen in a variety of conditions such as fasting, obesity, diabetes, and high-fat/low-carbohydrate diets (Yoo et al., 1991; Robertson et al., 2001; Pagano et al., 2002; Wang et al., 2003; Lieber, 2004, Ishii, 2004). The relationship between CYP2E1 and NASH was originally suggested in a rat nutritional model of NASH (Weltman et al., 1996) and was later confirmed in human NASH (Weltman et al., 1998), with CYP2E1 up-regulation being observed in clinical settings that are associated with steatohepatitis, namely, diabetes mellitus and obesity (Lucas et al., 1998). Furthermore, hepatic CYP2E1 protein expression and activity are higher in livers from obese patients with steatohepatitis than in those with uncomplicated steatosis (Chalasani et al., 2003) and correlated positively with the severity of liver damage (Videla et al., 2004a; Leclercq, 2004; Orellana et al., 2006), suggesting that CYP2E1 induction is related to progression of NASH.

The human CYP2E1 hepatic mRNA, protein, and enzyme activity exhibit an important interindividual variability (Lucas et al., 1993). It has been proposed that genetic polymorphisms of the gene encoding CYP2E1 could contribute to such variability and to the development of pathologies such as hepato-cellular carcinoma ( $\mathrm{Yu}$ et al., 1995) and alcoholic liver disease (Tsutsumi et al., 1994). In addition, profound ethnic differences in CYP2E1 allele frequencies have previously been reported among Asians, Caucasians and Africans, which may explain ethnic differences in related metabolic activity and disease (Stephens et al., 1994).

Several polymorphic sites are found in the CYP2E1 gene. Dra1 polymorphism in the intron 6 of the gene deletes a restriction site for the enzyme Dral due to a transversion from adenine to thymine in the base 7,668 , which is called "rare allele C" or CYP2E1*6 (Hu et al., 1997). The final effect of this change on CYP2E1 activity has not been determined. In addition, Rsa1 polymorphism consists in a transition from cytosine to thymine upstream of the gene in the regulatory region: 1,019. Furthermore, Pst1 polymorphism is produced by transversion from guanine to cytosine in the position 1,259, very close to Rsa1 polymorphism (Watanabe et al., 1994). These latter two polymorphisms are found in linkage disequilibrium and their rare allele is called c2 or CYP2E1*5B (Quiñones et al., 1999). The functional relevance of the Rsa1 polymorphism is due to its location in the binding site of the hepatic nuclear factor 1 (HNF-1), a liver-specific transcription factor that enhances the transcriptional activity of the human CYP2E1 promoter (Hayashi et al., 1991; Watanabe et al., 1994; Quiñones et al., 1999). Unlike alcoholic fatty liver disease (ASH), the metabolic features associated with NASH, such as fat accumulation, insulin resistance, and increased ketone bodies, would favor a higher transcriptional activity of the CYP2E1 gene (Yun et al., 1992; Zangar and Novak, 1997; Woodcroft et al., 2002). Based on these antecedents, the aim of this study was to investigate the role of functionally relevant CYP2E1 polymorphisms in NASH. For this purpose, the content and activity of CYP2E1 and the allele variants for the Dra1, Rsa1, and Pst1 polymorphisms were 
analyzed in relation to the clinical, histological, and pathophysiological aspects of NASH.

\section{METHODS}

\section{Patients and laboratory research}

Forty-eight voluntary women subjected to gastroplasty or gastrectomy with a gastrojejunal anastomosis were included in this study. A complete clinical history, including data on nutrition and alcohol consumption together with anthropometric measurements were obtained. Laboratory tests included liver enzymes, bilirubin, albumin, hepatitis $\mathrm{B}$ and $\mathrm{C}$ serology, and autoantibodies

(anti-nuclear, antimitochondrial, and anti-smooth muscle antibodies). In addition, serum levels of ferritin, transferrin saturation, ceruloplasmin, cholesterol, triacylglycerols, low-density lipoprotein, high-density lipoprotein, and glucose were also determined. The index of insulin resistance was evaluated by Homeostasis Model Assessment (HOMA), calculated as (fasting insulin $x$ fasting glucose)/22.5. Patients with significant alcohol consumption (more than $40 \mathrm{~g}$ of alcohol per week), previous use of steatogenic medications or any blood tests suggesting other specific liver diseases (e.g., viral hepatitis, autoimmune liver disease, primary biliary cirrhosis) or diabetes were excluded. Selected patients were subjected to a diet of $25 \mathrm{kcal} / \mathrm{kg}(30 \%$ lipids, $15 \%$ proteins), for at least 2 days prior to surgery. Liver biopsies of approx. 2 $\mathrm{cm}^{3}$ were taken during the surgery for histological diagnosis. A half of each liver samples were fixed in $10 \%$ formaldehyde and paraffin-embedded, and sections were stained with either haematoxylin/eosin or Van Gieson's stains. Sections of each liver biopsy were blindly observed and evaluated for histological abnormalities by means of a previously defined code (Videla et al., 2004b). Obese patients were divided into three groups: (a) normal group (normal liver histology); (b) patients with steatosis (5-100\% macrovesicular steatosis); and (c) patients with steatohepatitis (steatosis and lobular inflammation with hepatocyte ballooning, with or without fibrosis). The second half of the liver samples were stored at $-80^{\circ} \mathrm{C}$ for about $48 \mathrm{~h}$ until used for microsome preparation for immmunoblot.

The Ethics Committee of the Clinical Hospital of the Universidad de Chile approved the study protocol, according to the 1964 (Revised in October 2000) Declaration of Helsinki. Informed consent for using part of the blood and liver samples was obtained from all patients.

\section{Immunoblotting}

Liver microsomes were prepared by ultracentrifugation (Orellana et al., 2006) from at least $1 \mathrm{~g}$ of liver biopsies, and total microsomal protein content was measured according to Lowry et al. (1951), using bovine serum albumin (BSA) as standard. The liver CYP2E1 content was determined by Western blot. A polyclonal antibody to hepatic cytochrome P450 2E1 (Daiichi Pure Chemicals Co. Ltd., Tokyo, Japan) was used to detect the enzyme in $20 \mu \mathrm{g}$ of microsomal protein per lane in Western Blot experiments (Towbin et al., 1979). Alkaline phosphatase-linked secondary antibody was used, and the bands were stained with Nitroblue tetrazolium (NBT)/ 5-bromo-4-cloro-3-indolylphosphate (BCIP) solution. Quantification of CYP2E1 was performed using acetone-treated rat liver microsomes containing cytochrome P450 2E1 (3 pmol/blot) as standard (Daiichi Pure Chemicals Co. Ltd.).

\section{In vivo CYP2E1 activity assay}

CYP2E1 activity was measured using $\mathrm{CHZ}$ as an in vivo probe in patients prior to surgery. This muscle relaxant has been proposed as a specific probe for CYP2E1 activity (Lucas et al., 1993a). Subjects were asked to avoid certain foods (grapefruit, vegetables from the mustard-green family, and beverages containing xanthine and alcohol) for at least 72 hours. Any medications were discontinued one week before this test to reduce the chances of drug interference. Blood samples were collected for 2 hours after administering a $500 \mathrm{mg}$ 
dose of CHZ orally; blood samples from each group of patients were received in plastic tubes with EDTA, centrifuged immediately and the serum frozen at $-20^{\circ} \mathrm{C}$ until used. The serum concentrations of $\mathrm{CHZ}$ and 6-hydroxy-CHZ were separated and determined by reverse-phase highperformance liquid chromatography (HPLC), after de-conjugation with 2,000 units of $\beta$ glucuronidase at $37^{\circ} \mathrm{C}$ for 1 hour by using a LiChrospher ${ }^{\circledR} 100$ RP-18 $(5 \mu \mathrm{m})$ column and acetonitrile/acetic acid, 30/70 (v/v) at a flow of $1 \mathrm{ml} / \mathrm{min}$, measuring the absorbance at $285 \mathrm{~nm}$. The CYP2E1 activity was expressed as $6-\mathrm{OH}-\mathrm{CHZ} / \mathrm{CHZ}$ ratio.

\section{Blood samples and DNA extraction}

Blood samples were collected on EDTA from all women and used to obtain genomic DNA from peripheral leukocytes following the method of Miller et al. (1988). The genomic DNA was examined for purity at 260/280 $\mathrm{nm}$ absorption and re-purified with phenol/chloroform protocol as required. DNA was stored at $-30^{\circ} \mathrm{C}$ until used.

\section{Genotyping methods}

After DNA extraction, polymerase chain reaction $(\mathrm{PCR})$ based restriction fragment length polymorphism (RFLP) was used to examine the polymorphism of interest. All samples were submitted to separate amplifications followed by digestion with appropriate restriction enzymes. Dral alleles detection was carried out using the primers described by Hirvonen et al. (1993), yielding a 373 bp fragment used to amplify between 7421 and 7793 nucleotides inside intron 6 of the gene. For the Rsal and Pst 1 polymorphisms, primers yielding a $413 \mathrm{bp}$ fragment were used to amplify between -1372 and -960 nucleotides upstream of the gene to detect both sites (Rsal/Pst1) (Hayashi et al., 1991). The PCR products were subjected to digestion with Dral, Rsal and Pstl restriction enzymes at $37^{\circ} \mathrm{C}$ for $1 \mathrm{~h}$ (GIBCO BRL, Life Technologies, Inc., Gaithersburg, MD, USA). The samples were then analyzed by agarose 3\% gel electrophoresis (Bio-Rad Lab., Richmond, CA, USA).

\section{Statistical analysis}

Interval variables are expressed as means \pm SEM, with the indicated number of samples unable to be processed (missing data). For categorical variables, frequencies and percentages were used. The differences were considered statistically significant at $p<0.05$. To compare interval variables and categorical variables among different groups we employed Student $t$ test and $\mathrm{chi}^{2}$, respectively. Odds ratios (OR) and 95\% Confident Interval (CI95\%) were used to compare the magnitude of fatty liver disease risk between the different group.

\section{RESULTS}

Table I shows the general clinical and biochemical characteristics of the normal group and patients with steatosis and steatohepatitis. Age, HDL, LDL, fasting glucose, AST, $\gamma \mathrm{GT}$, bilirubin, and albumin are comparable among groups. However, significant differences are observed between normal and steatohepatitis groups in body mass index (BMI), triacylglycerols, fasting insulin, HOMA, and ALT, and between normal and steatosis groups in cholesterol and HOMA. Examples for genotypic analysis of Dral, Rsal, and Pst1 polymorphism are shown in Figure 1 (A and B), where patterns for obese women with different genotypes are observed after PCR amplification and restriction enzyme digestion. Table II shows the distribution of different Dral and Rsal/Pstl genotypes in the studied groups, where $\mathrm{C}^{*}$ correspond to a group of $\mathrm{CD}$ and $\mathrm{CC}$ genotypes and $\mathrm{c} 2 *$ correspond to a group of $\mathrm{c} 1 \mathrm{c} 2$ and $\mathrm{c} 2 \mathrm{c} 2$ (alleles with the nucleotide exchanges). The allele frequencies for $\mathrm{C}$ (fc) were 0.115 , 0.139 , and 0.235 for normal, steatosis, and steatohepatitis groups, respectively, whereas those for $\mathrm{c} 2$ (fc2) were 0.115 , 0.055 and 0.235 , respectively. The risk of steatosis and steatohepatitis in women carriers of $\mathrm{C}^{*}$-susceptibility allele variants was $71 \%$ greater compared with the normal group. In the case of $\mathrm{c} 2 *$, the risk was close to null value for steatosis. On the other hand, the risk of steatohepatitis in women 
carriers of $\mathrm{c} 2 *$-susceptibility allele was $75 \%$ greater compared with the normal group.

The immunodetection of the CYP2E1 enzyme in microsomes obtained from liver biopsies of women with normal liver histology, steatosis, or steatohepatitis was standardized using rat CYP2E1 (Fig. 2 A). The results obtained through band densitometry analysis of Western blots from patients with wild-type alleles (c1c1 and DD) show statistically significant increases in the amount of CYP2E1 in steatosis and steatohepatitis in relation to the normal group, $22 \%$ and $45 \%$ respectively (Fig. 2 B).

In order to analyze whether the observed increase in the immunodetected amount of CYP2E1 is reflected in the enzyme activity, we assayed the in vivo CYP2E1-dependent hydroxylation of $\mathrm{CHZ}$ in the studied groups, expressed as the ratio between the resulting product $6-\mathrm{OH}-\mathrm{CHZ}$ and the substrate $\mathrm{CHZ}$. The results showed comparable values in the steatosis and normal groups, whereas those in the steatohepatitis group were significantly higher than the normal group (35\%; $\mathrm{p}=0.027)$ (Fig. 3). Furthermore, in vivo CHZ hydroxylation and liver CYP2E1 content are significantly correlated $(r=0.59$; $\mathrm{p}=0.026$ ).

The analysis of the relationship between in vivo catalytic activity of CYP2E1, assayed as CHZ hydroxylase, and genotypes is shown in Figure 4. The results show that the increase in CYP2E1 activity is statistically significant for $\mathrm{c} 2 *$ comprising c1c2 and c2c2 genotypes (Fig. 4 A), whereas no significant association is observed between $\mathrm{CHZ}$ hydroxylation for $\mathrm{C}^{*}$ comprising $\mathrm{CD}$ and $\mathrm{CC}$ genotypes (Fig. 4 B).

TABLE 1

Clinical and biochemical characteristics of obese patients with non-alcoholic fatty liver disease with different degrees of liver injury

\begin{tabular}{lccccc}
\hline Parameters & \multicolumn{3}{c}{ Liver histology } \\
\cline { 2 - 5 } & $\begin{array}{c}\text { Normal (Controls) } \\
(\mathrm{n}=13)\end{array}$ & $\begin{array}{c}\text { Steatosis } \\
(\mathrm{n}=18)\end{array}$ & $\begin{array}{c}\mathrm{p} \text { Value } \\
(\mathrm{n}=17)\end{array}$ & Steatohepatitis & p Value \\
\hline Age (years) & $40 \pm 3.3$ & $43 \pm 4.3$ & 0.609 & $41 \pm 3.5$ & 0.841 \\
BMI $\left(\mathrm{kg} / \mathrm{m}^{2}\right)$ & $37 \pm 1.3$ & $36 \pm 2.1$ & 0.715 & $50 \pm 2.3$ & $<0.001^{*}$ \\
Cholesterol (mg/dL) & $151 \pm 12.0$ & $189 \pm 12.0$ & $0.038^{*}$ & $183 \pm 11.2$ & 0.064 \\
Triacylglycerols (mg/dL) & $107 \pm 15.0$ & $134 \pm 27.2$ & 0.441 & $189 \pm 33$ & $0.050^{*}$ \\
LDL (mg/dL) & $112 \pm 9.5$ & $126 \pm 10.5$ & 0.351 & $102 \pm 6.9$ & 0.390 \\
HDL (mg/dL) & $51 \pm 4.5$ & $43 \pm 3.5$ & 0.165 & $42 \pm 3.3$ & 0.110 \\
Fasting glucose (mmol/L) & $5.3 \pm 0.5$ & $5.9 \pm 0.4$ & 0.352 & $5.6 \pm 0.9$ & 0.791 \\
Fasting insulin ( $\mu \mathrm{UU} / \mathrm{ml})$ & $14.1 \pm 2.3$ & $25 \pm 4.5$ & 0.064 & $37 \pm 7.3$ & $0.013^{*}$ \\
HOMA & $3.3 \pm 0.7$ & $6.5 \pm 0.8$ & $0.008^{*}$ & $8.7 \pm 0.8$ & $<0.001^{*}$ \\
AST (IU/L) & $26 \pm 3.0$ & $36 \pm 7$ & 0.257 & $31 \pm 3.5$ & 0.306 \\
ALT (IU/L) & $32 \pm 3.2$ & $50 \pm 11$ & 0.186 & $48 \pm 5.5$ & $0.028^{*}$ \\
$\gamma$-GT (IU/L) & $39 \pm 6.5$ & $45 \pm 7.9$ & 0.584 & $37 \pm 3.2$ & 0.769 \\
Bilirubin ( mg/dL) & $0.6 \pm 0.1$ & $0.5 \pm 0.1$ & 0.497 & $0.6 \pm 0.1$ & 1.000 \\
Albumin (g/dL) & $4.3 \pm 0.2$ & $4.3 \pm 0.1$ & 1.000 & $4.1 \pm 0.1$ & 0.345 \\
\hline
\end{tabular}

Values represent means \pm SEM for the number (n) of subjects indicated.. Abbreviations: BMI, body mass index; LDL, low density lipoprotein; HDL, high density lipoprotein; AST, aspartate aminotransferase; ALT, alanine aminotransferase; $\gamma$-GT, $\gamma$-glutamyltranspeptidase;. HOMA, homeostasis model assessment. * Significant $\mathrm{p}$ values in relation to controls. 
TABLE 2

CYP2E1 genotype distribution and allele frequencies $(f)$ according to hepatic injury in obese patients with non-alcoholic fatty liver disease

\begin{tabular}{|c|c|c|c|c|c|c|c|}
\hline & & & & iver histolog & & & \\
\hline & $\begin{array}{l}\text { Normal } \\
\mathrm{n}(\%)\end{array}$ & $\begin{array}{l}\text { Steatosis } \\
\mathrm{n}(\%)\end{array}$ & ORa & $\mathrm{CI} 95 \%$ & $\begin{array}{c}\text { Steatohepatitis } \\
\mathrm{n}(\%)\end{array}$ & ORa & CI95\% \\
\hline Dral & & & & & & & \\
\hline DD & $10(21)$ & $13(27)$ & Ref & Ref & $10(21)$ & Ref & Ref \\
\hline $\mathrm{CD}$ & $3(6)$ & $5(10)$ & 1.71 & $0.27-10.65$ & $6(13)$ & 2.0 & $0.30-14.15$ \\
\hline $\mathrm{CC}$ & 0 & 0 & - & - & 1(2) & - & - \\
\hline $\mathrm{C}^{*}$ & $3(6)$ & $5(10)$ & 1.71 & $0.27-10.65$ & $7(15)$ & 1.71 & $0.30-9.59$ \\
\hline$f_{\mathrm{c}}$ & 0.115 & 0.139 & & & 0.235 & & \\
\hline Rsa1/ & & & & & & & \\
\hline $\mathrm{c} 1 \mathrm{c} 1$ & $10(21)$ & $16(33)$ & Ref & Ref & $10(21)$ & Ref & Ref \\
\hline $\mathrm{c} 1 \mathrm{c} 2$ & $3(6)$ & $2(4)$ & 0.98 & $0.07-14.18$ & $6(13)$ & 2.0 & $0.30-14.15$ \\
\hline $\mathrm{c} 2 \mathrm{c} 2$ & 0 & 0 & - & - & $1(2)$ & - & - \\
\hline $\mathrm{c} 2 *$ & $3(6)$ & 2(4) & 0.98 & $0.07-14.18$ & $7(15)$ & 1.75 & $0.10-3.17$ \\
\hline$f \mathrm{c} 2$ & 0.115 & 0.055 & & & 0.235 & & \\
\hline
\end{tabular}

Abbreviations: f, frequency of the indicated alleles; Ref, Reference allele (wild type); ORa, Age adjusted Odd ratios; CI95\%, 95\% Confident interval.

\section{DISCUSSION}

The pathogenic mechanisms underlying the development of NASH are not completely understood, particularly how apparently diverse etiologies such as alcohol consumption and obesity can give rise to similar histological features (Lieber, 2004; Ishii, 2004). Contrarily to NASH, several studies related to CYP2E1 polymorphisms and alcoholic fatty liver disease (ASH) are available, although they are highly contradictory. In fact, in the Japanese population, Tsutsumi et al. showed an association between c2 allele and $\mathrm{ASH}$ (Lucas et al., 1993b), while Maezawa et al (1994) reported an association with c1 allele. In the North American population, Carr et al. found no association between Rsal polymorphism and ASH (Carr et al., 1995), whereas Pirmohamed et al. showed a significant correlation between c2 allele and ASH [Pirmohamed et al., 1995). These observed differences could be due to: (i) clinical differences among patients; (ii) ethnic variations in the studied populations; and (iii) the mechanism for the increase of CYP2E1 activity involved. In ASH, upregulation of hepatic CYP2E1 activity is exerted at the post-translational level due to ethanol effect on protein stabilization (Carroccio et al., 1994), therefore no association with polymorphisms should be expected. Conversely, metabolic conditions associated with NASH could act at genetic level modifying the transcriptional activity of the CYP2E1 gene, which in turn, may also be influenced by polymorphisms.

Data presented in this work for in vivo CYP2E1 activity, immunodetected amounts of liver biopsy CYP2E1, and genetic polymorphisms, were obtained from nondiabetic, morbidly obese patients, excluding diabetic women and men, as previous studies show controversial results in relation to the effect of glucose on hepatic CYP2E1 amount and activity (Wang et al., 2003; Woodcroft et al., 2002) and sex as a factor in CYP2E1 levels (Dekant et al., 1995). 
A
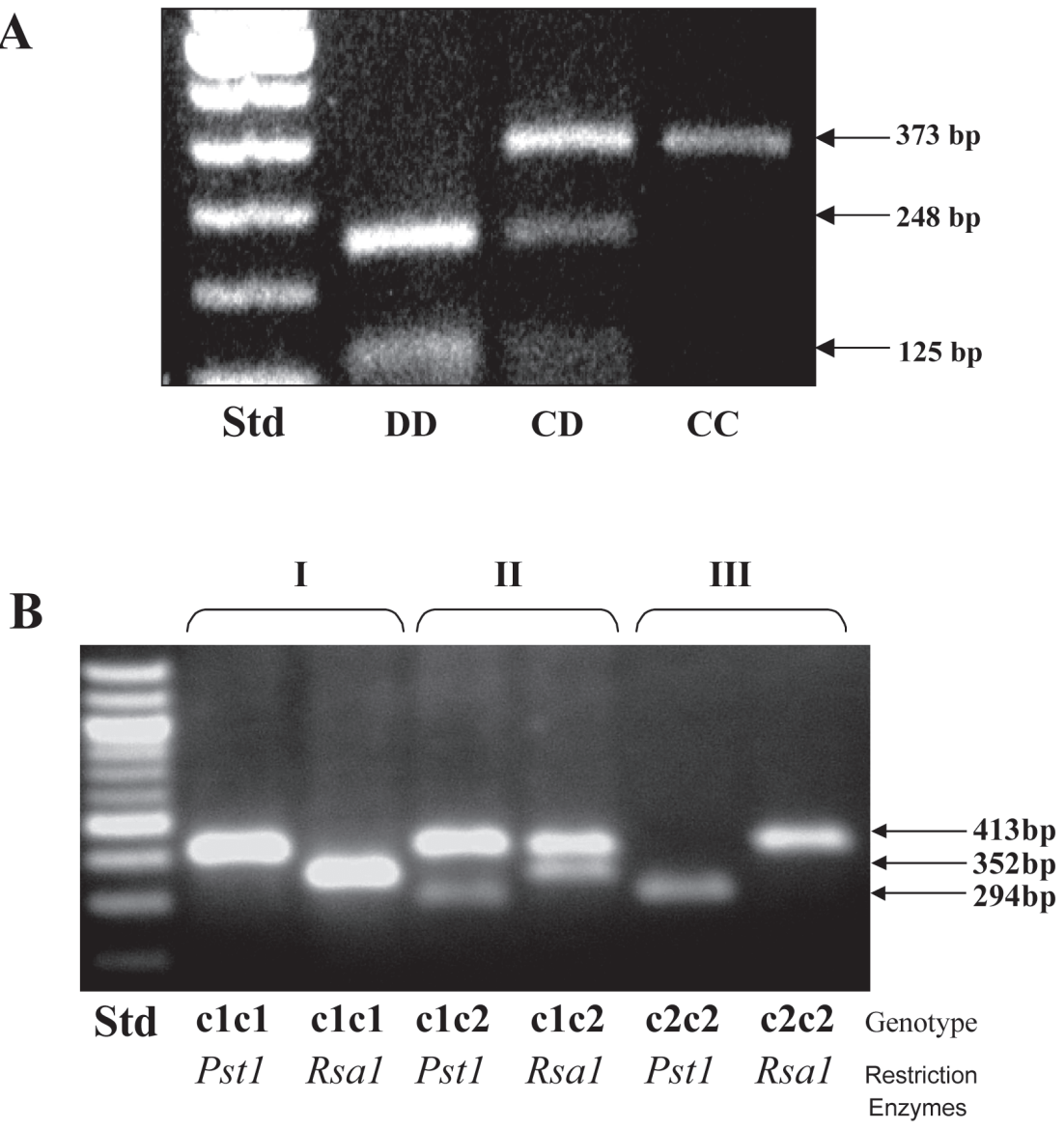

Figure 1: Representative profiles of RFLP-PCR analysis of CYP2E1 for Dral polymorphism (A) and Rsal and Pstl polymorphisms (B) in obese patients. In A, patients exhibit DD, CD, and CC genotypes. The $248 \mathrm{bp}$ and $125 \mathrm{bp}$ fragments obtained after Dral digestion represent wild alleles (D) and the $373 \mathrm{bp}$ fragment corresponds to the rare allele (C). In B, the $352 \mathrm{bp}$ fragment found after Rsal digestion represents the wild allele (c1) and that of $413 \mathrm{bp}$, the rare allele (c2). The 294 bp fragment obtained after Pstl digestion corresponds to the rare allele (c2) and that of $413 \mathrm{bp}$ represents the wild-type allele (c1).

Patients studied show liver function tests within normal ranges, in agreement with previous observations (García-Monzon et al., 2000; Mofrad et al., 2003). In this clinical setting, obese patients with steatosis exhibited hepatic CYP2E1 levels $22 \%$ higher than those with normal liver histology, which is not reflected in significant changes in the in vivo CYP2E1 activity assessed by the $\mathrm{CHZ}$ hydroxylation assay. In patients with NASH, however, liver CYP2E1 content is $45 \%$ higher than normal values in concomitance with the $15 \%$ enhancement of in vivo CYP2E1 activity, suggesting the attainment of a functionally significant CYP2E1 induction in these patients. Data reported indicate that in vivo $\mathrm{CHZ}$ hydroxylation constitutes a non-invasive and reliable indicator of CYP2E1 activity under conditions of enhanced gene expression. Enhancement in liver CYP2E1 content and activity with severe morphological alterations assessed by liver histology is observed in patients with insulin resistance, independently on CYP2E1 genotype. These observations suggest that CYP2E1 induction is a major factor for liver injury in obese patients with NASH, probably due to substantial attenuation of the repressive effect of 
insulin on CYP2E1 expression (Fig. 5), which is normally exerted at transcriptional and post-transcriptional levels (Woodcroft et al., 2002). In addition, specific relevant polymorphic sites in the CYP2E1 gene may represent contributory factors for CYP2E1 induction (Fig. 5), as the ethanol effect in ASH $(23,38,40)$. In fact, CYP2E1 variant allele c2 shows a statistically significant association with the in vivo $\mathrm{CHZ}$ hydroxylase activity, which in turn is related to liver injury in obese women. In vitro studies have shown that rare $\mathrm{c} 2$ allele is associated with higher transcriptional activity protein expression and enzyme activity than the wild-type c1 allele (Hayashi et al., 1991; Watanabe et al., 1994).

Recent works suggest that the main factor responsible for increase of CYP2E1 expression is insulin rather than ketone bodies, both in diabetic or fasting mammals (Woodcroft et al., 2002) and in rat hepatocytes with metabolic syndrome associated with NASH (Pagano et al., 2002). Through kinases IP3, P70 S6 and Src, this hormone would exert a suppressive effect on the CYP2E1 expression by the concerted action of enhanced CYP2E1 mRNA turn-over and inhibition of


\section{Liver Histology}

Figure 2: (A) Representative SDS-PAGE of microsomal protein (20 mg per well) of liver biopsy samples from obese women with normal liver histology and patients with steatosis or steatohepatitis, using 3pmol/well of standard rat CYP2E1 (MW= $56 \mathrm{Kda})$ for quantification of the CYP2E1 amount. (B) Respective densitometric quantification expressed as means \pm SEM for the indicated number in parenthesis of patients (missing data $=11$ ); p-values are calculated in relation to the normal group (normal liver histology). 


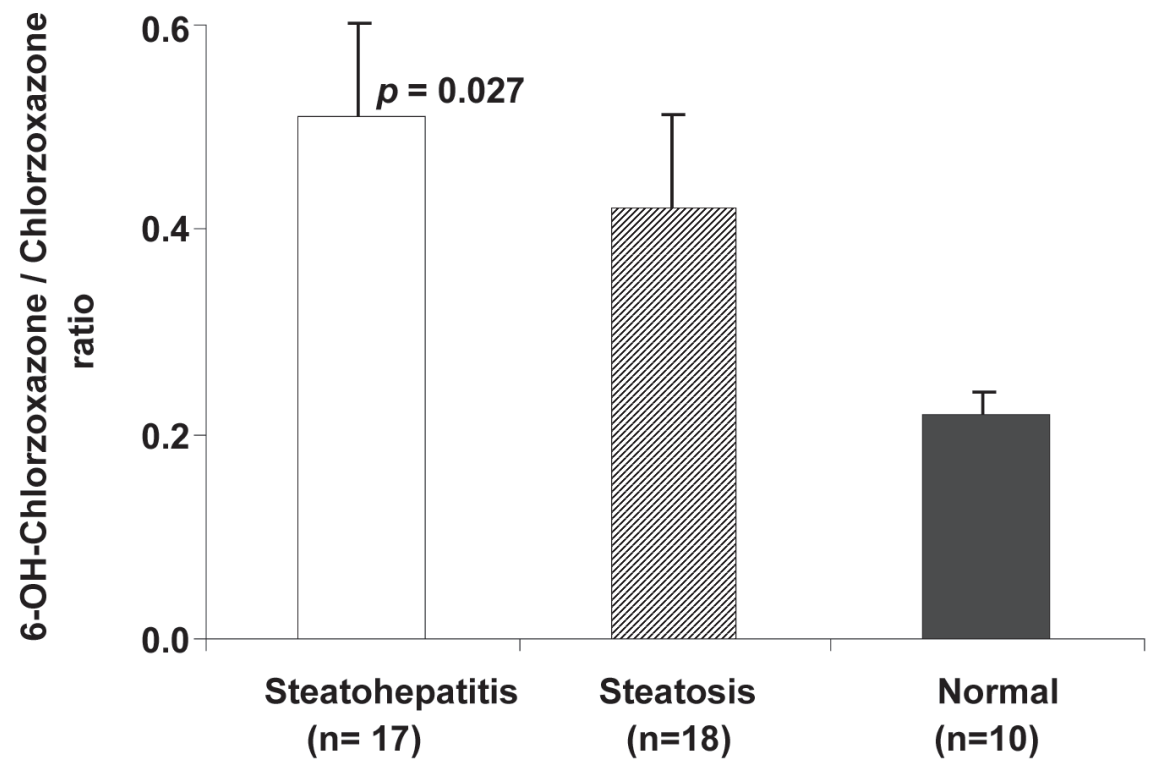

\section{Liver Histology}

Figure 3: In vivo chlorzoxazone (CHZ) hydroxylase activity of CYP2E1 in obese patients with normal liver histology and patients with steatosis or steatohepatitis. Values represent the means \pm SEM for the indicated number of patients (missing data =3), expressed as the 6-hydroxy-CHZ (6$\mathrm{OH}-\mathrm{CHZ} / \mathrm{CHZ}$ ratios; p-values are calculated in relation to the normal group (normal liver histology).

A

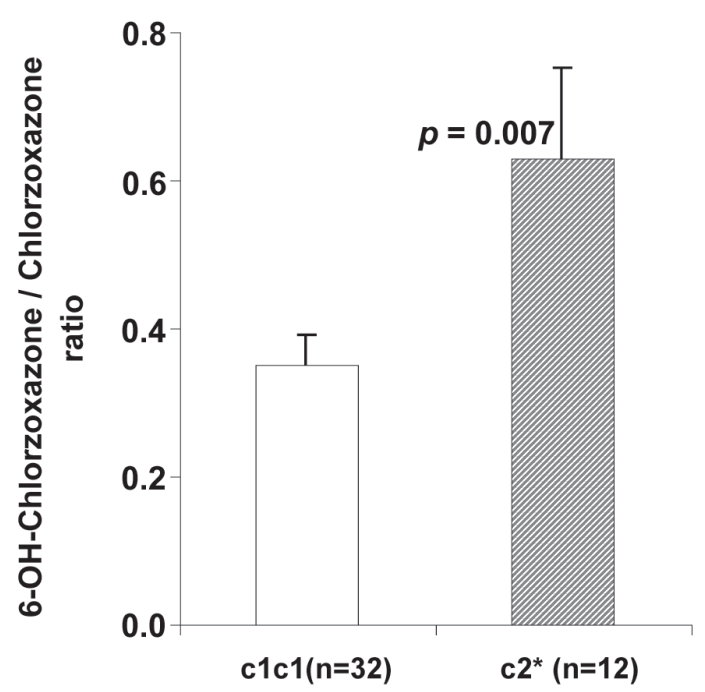

Rsa1 / Pst1 Genotype
$\mathrm{B}$

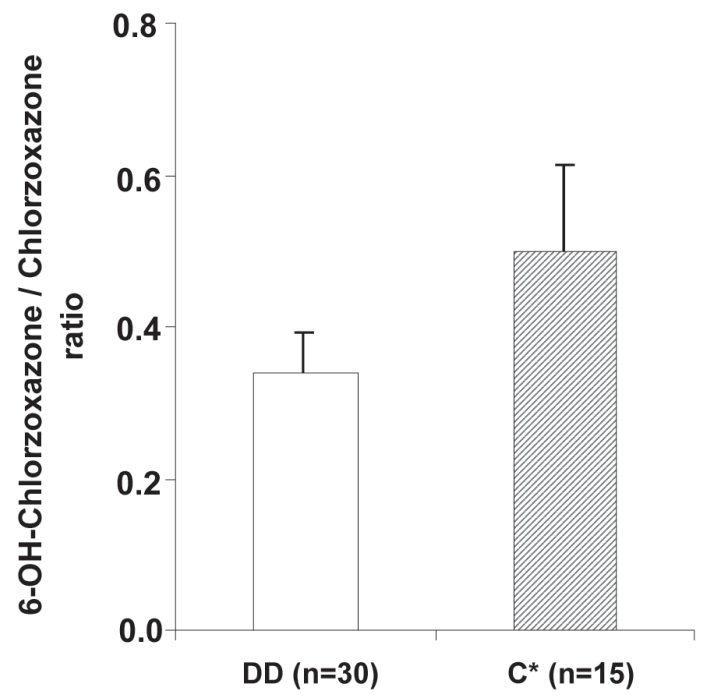

Dra1 Genotype

Figure 4: Analysis of in vivo chlorzoxazone hydroxylase activity in wild-type and rare genotypes of CYP2E1 in obese women (missing data $=3$ ). (A) Rsal/Pst1 genotypes, in which $\mathrm{c} 2 *$ correspond to c1c2 or c2c2 genotypes. (B) Dral genotype, in which $\mathrm{C}^{*}$ corresponds to CD or CC genotypes. The $\mathrm{p}$-values shown are obtained from comparison between rare and wild-type genotypes. 




Figure 5: Factors that influence liver CYP2E1 expression, reactive O2 species (ROS) production, and development of nonalcoholic steatohepatitis (NASH) associated with obesity. Abbreviations: $\mathrm{NF}-\kappa \mathrm{B}$, nuclear factor- $\mathrm{B}$; AP-1, activating protein-1; AA, arachidonic acid; LP, lipid peroxidation; $\mathrm{PC}$, protein carbonylation; DNAox, DNA oxidation.

transcription of the gene. However, Schattenberg et al. (2005) postulated that overexpression of CYP2E1 leads to impairment of hepatic insulin signaling (down-regulation), potentially contributing to insulin resistance associated with $\mathrm{NASH}$, an effect that may be due to the ability of CYP2E1 to induce oxidative stress (Fig. 5).

Together, these issues indicate that the relationship between NASH and insulin resistance is complex, therefore pointing to further studies of genetic expression factors on CYP2E1 in NASH, in addition to metabolic and environmental factors.

On the other hand, it has been shown that CYP2E1 genetic polymorphisms may avoid the down-regulation of transcriptional activity of this gene by proinflammatory cytokines, leading to more severe pathology due to an increase in the toxic potential of the enzyme (Mofrad et al., 2003). In this respect, changes in HNF1 $\alpha$ binding to the CYP2E1 promoter region also have been suggested as potential suppression mechanisms of CYP2E1 expression (Roe et al., 2001; Hakkola et al., 2003), where Rsal polymorphism could affect the negative feedback regulation mediated by cytokines. Our results show that CYP2E1*5B genetic polymorphism, which has been related to increase of CYP2E1 expression (Hayashi et al., 1991; Watanabe et al., 1994), influence the significant statistical association between CYP2E1 level and liver injury. 
In conclusion, polymorphism of CYP2E1 and insulin resistance are associated with higher levels and activity of the enzyme in obese patients with NASH, which have been related to increased risk of liver damage through enhancement of ROS production (Fig. 5). Therefore, in NASH etiology the occurrence of genetic polymorphisms increasing CYP2E1 expression could represent susceptibility factors to acquire insulin resistance mediated by oxidative stress.

\section{ACKNOWLEDGEMENTS}

This work was supported by grant 1060105 from FONDECYT, Santiago, Chile. The authors want to thanks Drs. Jorge Contreras, Raúl Lazarte, Jorge Rojas, Fernando Maluenda Juan Carlos Díaz and Patricio Burdiles for their clinical assistance.

\section{REFERENCES}

ANGULO P, KEACH JC, BATTS KP, LINDOR KD (1999) Independent predictors of liver fibrosis in patients with nonalcoholic steatohepatitis. Hepatology 30: 1356-1362

CARR LG, HARTLEROAD JY, LIANG YB, MENDENHALL C, MORITZ T, THOMASSON H, (1995) Polymorphism at the P-450IIE1 locus is not associated with alcoholic liver disease in caucasian men. Alcohol Clin Exp Res 19: 182-184

CARROCCIO A, WU D, CEDERBAUM AI (1994) Ethanol increases content and activity of human cytochrome P4502E1 in a transduced HepG2 cell line. Biochem Biophys Res Commun 203: 727-733

CHALASANI N, GORSKI C, ASGHAR M, ASGHAR A, FORESMAN B, HALL SD, CRABB DW (2003) Hepatic cytochrome P4502E1 activity in nondiabetic patients with nonalcoholic steatohepatitis. Hepatology 37(3): 544-550

DEKANT W, FRISCHMANN C, SPEERSCHNEIDER P (1995) Sex, organ and species specific bioactivation of chloromethane by cytochrome P4502E1. Xenobiotica 25(11): 1259-1265

FERNÁNDEZ V, MASSA L, QUIÑONES L, SIMONGIAVAROTTI KA, GIAVAROTTI L, D'ALMEIDA V, AZZALIS LA, JUNQUEIRA VBC, VIDELA LA (2003) Effects of ' $\gamma$-hexachlorocyclohexane and L-3,3',5triiodothyronine on rat liver cytochrome P4502E1dependent activity and content in relation to microsomal superoxide radical generation. Biol Res 36: 359-365

GARCÍA-MONZON C, MARTIN-PÉREZ E, IACONO OL, FERNÁNDEZ-BERMEJO M, MAJANO PL, APOLINARIO A, LARRAÑAGA E, MORENOOTERO R (2000) Characterization of pathogenic and prognostic factors of nonalcoholic steatohepatitis associated with obesity. J Hepatol 33: 716-724
GONZÁLEZ FJ (2005) Role of cytochromes P450 in chemical toxicity and oxidative stress: Studies with CYP2E1. Mutat Res 569: 101-110

HAKKOLA J, HU Y, INGELMAN-SUNDBERG M (2003) Mechanisms of down-regulation of CYP2E1 expression by inflammatory cytokines in rat hepatoma cell. J Pharmacol Exp Ther 304: 1048-1055

HAYASHI S, WATANABE J, KAWAJIRI K (1991) Genetic polymorphisms in the 5'-flanking region change transcriptional regulation of the human cytochrome P450IIE1 gene. J Biochem (Tokyo) 110: 559-565

HIRVONEN A, HUSGAFVEL-PURSIAINEN K, ANTTILA S, KARJALAINEN A, VAINIO H (1993) The human CYP2E1 gene and lung cancer: DraI and RsaI restriction fragment length polymorphisms in a Finnish study population. Carcinogenesis 14: 85-88

HU Y, OSCARSON M, JOHANSSON I, YUE QY, DAHL ML, TABONE M, ARINCÒ S, ALBANO E, INGELMAN-SUNDBERG M (1997) Genetic polymorphism of human CYP2E1: Characterization of two variant alleles. Mol Pharmacol 51: 370-376

ISHII H (2004) Common pathogenic mechanisms in ASH and NASH. Hepatol Res 28(1): 18-20

JAMES OFW, DAY CP (1998) Non-alcoholic steatohepatitis (NASH): A disease of emerging identity and importance. J Hepatology 29: 495-501

LECLERCQ IA (2004) Antioxidant defence mechanisms: New players in the patogenesis of non-alcoholic steatohepatitis? Clin Sci (Lond) 106(3): 235-7

LIEBER CS (2004) CYP2E1: From ASH to NASH. Hepatol Res 28(1): 1-11

LOWRY OH, ROSEBROUGH NJ, FARR AL, RANDALL RJ (1951) Protein measurement with the Folin phenol reagent. J Biol Chem 193: 265-275

LUCAS D, BERTHOU F, GIRRE C, POITRENAUD F, MÉNEZ JF (1993a) High-performance liquid chromatographic determination of $\mathrm{CHZ}$ and 6hydroxyCHZ in serum: A tool for indirect evaluation of cytochrome P4502E1 activity in humans. J Chromatogr 622: 79-86

LUCAS D, BERTHOU F, DREANO Y, LOZAC'H P, VOLANT A, MÉNEZ JF (1993b) Comparison of levels of cytochromes P-450, CYP1A2, CYP2E1, and their related monooxygenase activities in human surgical liver samples. Alcohol Clin Exp Res 17: 900-905

LUCAS D, FAREZ C, BARDOU LG, VAISSE JR, BERTHOU F (1998) Cytochrome P450 2E1 activity in diabetic and obese patients as assessed by chorzoxazone hydroxylation. Fundamental and Clinical Pharmacology 12: 553-558

LUDWIG J, VIGGIANO TR, MCGILL DB, OH BJ (1980) Nonalcoholic steatohepatitis: Mayo Clinic experiences with a hitherto unnamed disease. Mayo Clin Proc 55: 434-438

MAEZAWA Y, YAMAUCHI M, TODA G (1994) Association between restriction fragment length polymorphism of the human cytochrome P450IIE1 gene and susceptibility to alcoholic liver cirrhosis. Am J Gastroenterol 89: 561-565

MATTEONI CA, YOUNOSSI ZM, GRAMLICH T, BOPARAI N, LIU YC, MCCULLOUGH AJ (1999) Nonalcoholic fatty liver disease: A spectrum of clinical and pathological severity. Gastroenterology 116: 14131419

MILLER SA, DYKES DD, POLESKY HF (1988) A simple salting out procedure for extracting DNA from human nucleated cells. Nucleic Acids Res 16: 1215

MOFRAD P, CONTOS MJ, HAQUE M, SARGEANT C, FISHER RA, LUKETIC VA, STERLING RK, 
SHIFFMAN ML, STRAVITZ RT, SANYAL AJ (2003) Clinical and histologic spectrum of nonalcoholic fatty liver disease associated with normal ALT values. Hepatology 37: 1286-1292

ORELLANA M, RODRIGO R, VARELA N, ARAYA J, PONIACHIK J, CSENDES A, SMOK G, VIDELA L (2006) Relationship between in vivo CHZ hydroxylation, hepatic cytochrome P450 2E1 content and liver injury in obese non-alcoholic fatty liver disease patients. Hepatology Research 34: 57-63

PAGANO G, PACINI G, MUSSO G, GAMBINO R, MECCA F, DEPETRIS N, CASSADER M, DAVID E, CAVALLO-PERIN P, RIZZETTO M (2002) Nonalcoholic steatohepatitis, insulin resistance, and metabolic syndrome: Further evidence for an etiologic association. Hepatology 35: 367-372

PIRMOHAMED M, KITTERINGHAM NR, QUEST LJ, ALLOTT RL, GREEN VJ, GILMORE IT, PARK BK (1995) Genetic polymorphism of cytochrome P4502E1 and risk of alcoholic liver disease in Caucasians. Pharmacogenetics 5: 351-357

QIU L, LINDER MW, ANTONIO-GREEN DM, VALDÉS R JR (2004) Suppression of cytochrome P450 2E1 promoter activity by interferon-g and loss of response due to the $-71 \mathrm{G}>\mathrm{T}$ nucleotide polymorphism of the CYP2E1*7B allele. J Pharmacol Exp Ther 308: 284288. **not cited in paper**

QUINONES L, BERTHOU F, VARELA N, SIMON B, GIL L, LUCAS D (1999) Ethnic susceptibility to lung cancer: differences in CYP2E1, CYP1A1 and GSTM1 genetic polymorphisms between French Caucasian and Chilean populations. Cancer Lett 141: 167-171

RATZIU V, GIRAL P, CHARLOTTE F, BRUCKERT E, THIBAULT V, THEODOROU I, KHALIL L, TURPIN G, OPOLON P, POYNARD T (2000) Liver fibrosis in overweight patients. Gastroenterology 118: 1117-1123

ROBERTSON G, LECLERCQ I, FARRELL GC (2001) Nonalcoholic steatosis and steatohepatitis. II. Cytochrome P-450 enzymes and oxidative stress. Am J Physiol Gastrointest Liver Physiol 281: 1135-1139

ROE AL, POLOYAC SM, HOWARD G, SHEDLOFSKY SI, BLOUIN RA (2001) The effect of endotoxin on hepatocyte nuclear factor 1 nuclear protein binding: Potential implications on CYP2E1 expression in the rat. J Pharm Pharmacol 53: 1365-1371

SCHATTENBERG JM, WANG Y, SINGH R, RIGOLI RM, CZAJA MJ (2005) Hepatocyte CYP2E1 overexpression and steatohepatitis lead to impaired hepatic insulin signalling. J Biol Chem 280 (11): 9887 9894

STEPHENS EA, TAYLOR JA, KAPLAN N (1994). Ethnic variation in the CYP2E1 gene: Polymorphism analysis of 695 African-Americans, European-Americans and Taiwanese. Pharmacogenetics 4: 185-192

TOWBIN H, STAEHELIN T, GORDON J (1979). Electrophoretic transfer of proteins from polyacrylamide gels to nitrocellulose sheets: Procedure and some applications. Proc Natl Acad Sci USA 76: $4350-4354$

TSUTSUMI M, TAKADA A, WANG JS (1994). Genetic polymorphisms of cytochrome $\mathrm{P} 4502 \mathrm{E} 1$ related to the development of alcoholic liver disease. Gastroenterology 107: 1430-1435

VIDELA L, RODRIGO R, ORELLANA M, FERNÁNDEZ $\mathrm{V}$, TAPIA $\mathrm{G}$, QUIÑONES L, VARELA $\mathrm{N}$, CONTRERAS J, LAZARTE R, CSENDES A, ROJAS J, MALUENDA J, BURDILES P, DÍAZ JC, SMOK G, THIELEMANN L, PONIACHIK J (2004a) Oxidative stress-related parameters in the liver of non-alcoholic fatty liver disease patients. Clinical Science 106(3): 261-268

VIDELA LA, RODRIGO R, ARAYA J, PONIACHIK J (2004b) Oxidative stress and depletion of hepatic longchain polyunsaturated fatty acids may contribute to nonalcoholic fatty liver disease. Free Radic Biol Med 37: 1499-1507

WANG Z, HALL SD, MAYA JF, LI L, ASGHAR A, GORSKI JC (2003) Diabetes mellitus increases the in vivo activity of cytochrome P450 $2 \mathrm{E} 1$ in humans. Br J Clin Pharmacol 55: 77-85

WATANABE J, HAYASHI S, KAWAJIRI K (1994) Different regulation and expression of the human CYP2E1 gene due to the RsaI polymorphism in the 5'flanking region. J Biochem (Tokyo) 116: 321-326

WELTMAN MD, FARRELL GC, HALL P, INGELMANSUNDBERG M, LIDDLE C (1998) Hepatic cytochrome P450 2E1 is increased in patients with nonalcoholic steatohepatitis. Hepatology 27: 128-133

WELTMAN MD, FARRELL GC, LIDDLE C (1996) Increased hepatocyte CYP2E1 expression in a rat nutritional model of hepatic steatosis with inflammation. Gastroenterology 111: 1645-1653

WOODCROFT KJ, HAFNER MS, NOVAK RF (2002) Insulin signaling in the transcriptional and posttranscriptional regulation of CYP2E1 expression. Hepatology 35: 263-273

YOO JS, NING SM, PANTUCK CB, PANTUCK EJ, YANG CS (1991) Regulation of hepatic microsomal cytochrome P450IIE1 level by dietary lipids and carbohydrates in rats. J Nutr 121: 959-965

YU MW, GLADEK-YARBOROUGH A, CHIAMPRASERT S, SANTELLA RM, LIAW YF, CHEN CJ (1995) Cytochrome P450 2E1 and glutathione S-transferase M1 polymorphisms and susceptibility to hepatocellular carcinoma. Gastroenterology 109: 1266-1273

YUN YP, CASAZZA JP, SOHN DH, VEECH RL, SONG BJ (1992) Pretranslational activation of cytochrome P450IIE during ketosis induced by a high fat diet. Mol Pharmacol 41: 474-479

ZANGAR RC, NOVAK RF (1997) Effects of fatty acids and ketone bodies on cytochromes P450 2B, 4A, and 2E1 expression in primary cultured rat hepatocytes. Arch Biochem Biophys 337: 217-224 